\title{
ROZSZERZONY FILTR KALMANA JAKO ESTYMATOR STANU W UKLADZIE WAHADLA ODWRÓCONEGO Z NAPĘDEM INERCYJNYM
}

\author{
Jarosław Gośliński, Adam Owczarkowski \\ Politechnika Poznańska, Wydział Elektryczny, Instytut Automatyki i Inżynierii Informatycznej
}

Streszczenie. W pracy przedstawione jest wyprowadzenie petnego obserwatora wektora stanu dla wahadła odwróconego z napędem inercyjny. Wahadło odwrócone z napędem inercyjnym stanowi mechanizm nieliniowy który posiada więcej stopni swobody niż wymuszeń. W celu poprawnego sterownia postuluje się o znajomość wszystkich zmiennych stanu. W pracy przedstawiony zostal model wahadta. Nastepnie autorzy dokonali dyskretyzacji modelu oraz zapisu modelu do postaci macierzowej, ostatecznie przedstawiony zostat obserwator bazujacy na wyprowadzonym modelu oraz wyniki jego działania.

Słowa kluczowe: Rozszerzony Filtr Kalmana, Wahadło odwrócone z napędem inercyjnym.

\section{EXTENDED KALMAN FILTER AS A FULL STATE OBSERVER IN APPLICATION OF THE INERTIA WHEEL PENDULUM}

Abstract. This paper presents derivation of the full state observer for an inverted, inertia wheel pendulum (IWP). This is a non-linear, underactuated mechanical system and therefore it has more degrees of freedom than control variables. In order to control this mechanical system properly, knowledge of all state variables is needed. In this paper, authors presented IWP's model, which was later written in matrix form. Finally, based on the model, full state observer was derived. In the end its results were shown.

Keywords: Inertia wheel pendulum, Extended Kalman Filter.

\section{Wstęp}

Odwrócone wahadło $\mathrm{z}$ napędem inercyjny, to urządzenie mechaniczne, które pierwszy raz zostało opisane w [3]. Od tego czasu powstało wiele prac, których celem było określenie prawidłowego sterowania dla takiego układu mechanicznego. Tego typu urządzenie mechaniczne jest szczególne w swoim rodzaju - pozwala ono na utrzymywanie równowagi w pojazdach dwukołowych. Tym samym może służyć jako moduł stabilizacyjny $\mathrm{w}$ elektrycznych urządzeniach transportowych. Wahadło $\mathrm{z}$ napędem inercyjnym jest jednym $\mathrm{z}$ wielu typów wahadeł odwróconych, natomiast jego budowa została opisana w rozdziale pt.: „Wprowadzenie do modelu matematycznego”. W kolejnym rozdziale, opisany został model matematyczny rozpatrywanego wahadła. Wahadło to posiada jedno sterowanie (prąd silnika) oraz grupę wyjść - zmiennych stanu, z których część jest estymowana przy użyciu klasycznego filtru Kalmana (fuzja sensorów), a pozostała część jest mierzona przy użyciu sensorów (enkoder, żyroskop oraz akcelerometr). W związku $\mathrm{z}$ problemem zakłóceń oraz $\mathrm{z}$ potrzebą posiadania wszystkich zmiennych stanu możliwie zbliżonych do wartość rzeczywistych, wprowadzony został estymator stanu, opisany w rozdziale trzecim. Wyniki działania estymatora oraz ich porównanie z pomiarami zostały przedstawione $\mathrm{w}$ rozdziale czwartym. W ostatnim punkcie autorzy dokonali podsumowania i wyciągnięcia wniosków z przeprowadzonych prac.

\section{Wprowadzenie do modelu matematycznego}

Przechodzac do modelu matematycznego wymagana jest wiedza o budowie omawianego wahadła. Wahadło składa się ze sztywnej konstrukcji na której zamontowany jest silnik prądu stałego, wyposażony w koło zamachowe. Cała konstrukcja jest połączona $\mathrm{z}$ podłożem za pomocą dwóch kół. Dzięki temu odebrany jest jeden stopień swobody natomiast możliwy jest ruch na boki oraz do przodu i tyłu. Konstrukcja omawianego wahadła została pokazana na rysunku 1 , natomiast na rysunku 2 pokazano jeden $\mathrm{z}$ tłumików hydraulicznych (czerwona ramka), których zastosowanie pozwoliło wyeliminować niepożądany efekt przewrotu wahadła.

Celem układu sterującego wahadła jest utrzymanie kąta zerowego (licząc od pionu) w osi Y (oś oznaczona na rysunku 1). Jest to możliwe poprzez rozpędzanie oraz hamowanie koła zamachowego. Szczegóły działania wahadła zostały opisane w [1].

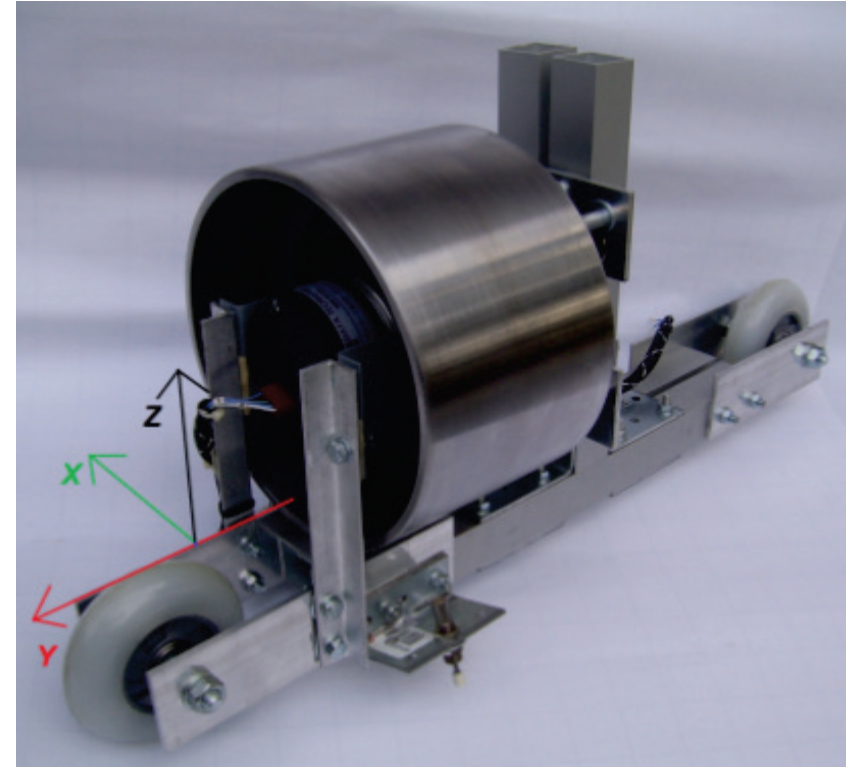

Rys. 1. Konstrukcja wahadta

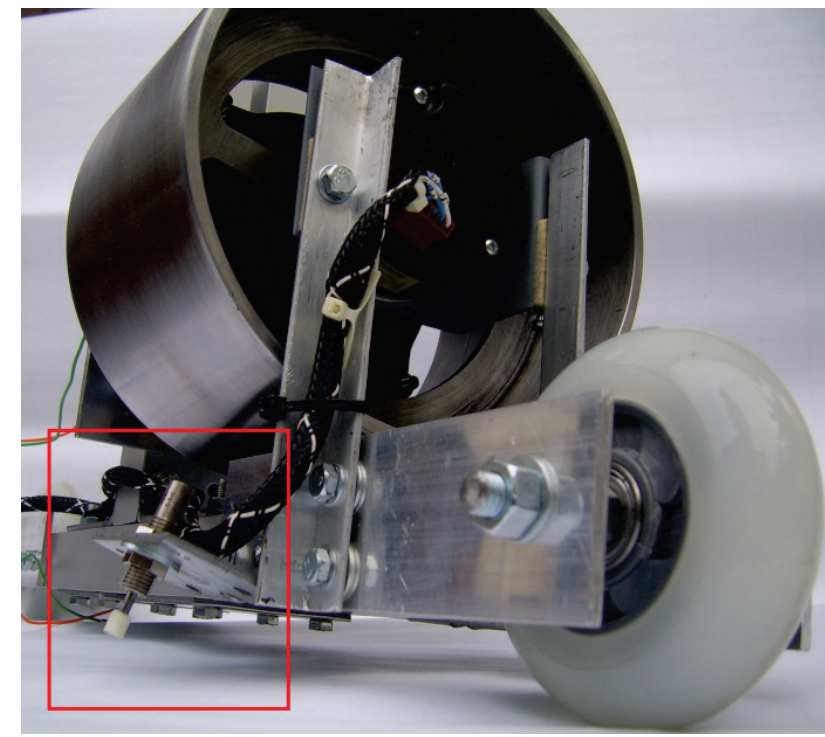

Rys. 2. Konstrukcja wahadła wraz z oznaczonym tlumikiem hydraulicznym 
Wahadło poza unikatowym rozwiązaniem konstrukcyjnym, posiada układ sterownika opartego o mikroprocesor ADUC7026 firmy Analog Devices którego wykorzystanie umożliwiło realizację komunikacji wskazanej na rysunku 3.

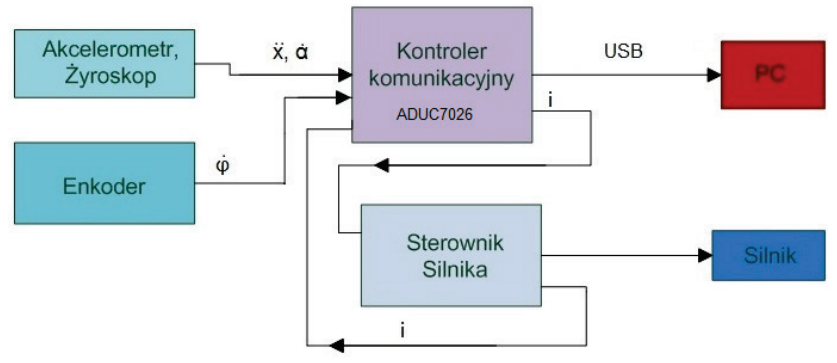

Rys. 3. Kontroler komunikacyjny wraz z systemem sensorycznym oraz układem wykonawczym wahadta.

Obok procesora, bardzo ważny jest układ sensoryczny. Na potrzeby niniejszej pracy wykorzystano precyzyjny czujnik inercyjny składający się $\mathrm{z}$ trzech akcelerometrów i trzech żyroskopów oznaczony symbolem ADIS16355 i pokazany na rysunku 4.

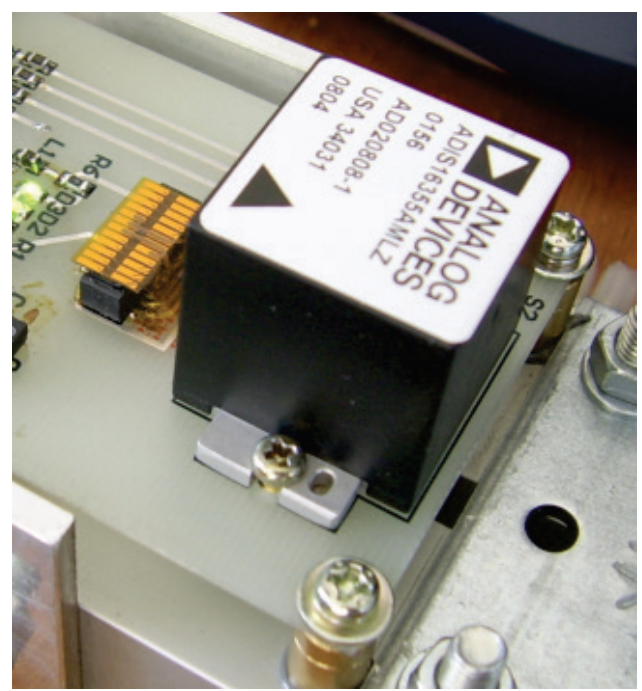

Rys. 4. Precyzyjny czujnik inercyjny ADIS16355

\section{Model matematyczny}

Model matematyczny omawianego wahadła można przedstawić za pomocą równań stanu. Jest to jednak wygodne tylko wtedy, gdy model nie posiada wyrażeń nieliniowych. W omawianym przypadku występuje nieliniowość w postaci funkcji trygonometrycznej. Zatem w pierwszej części model zostanie przedstawiony za pomocą równań:

$$
\begin{gathered}
\ddot{\alpha}=\frac{I_{k} \ddot{\phi}}{I_{r}+I_{k}}+\frac{m_{c} g l_{p} \sin (\alpha)}{I_{r}+I_{k}}-\frac{b_{\alpha} \dot{\alpha}}{I_{r}+I_{k}}, \\
\ddot{\phi}=\frac{k i-b_{\phi} \dot{\phi}}{I_{k}}
\end{gathered}
$$

gdzie:

$\alpha$ - to kąt odchylenia wahadła od pionu (w osi Y),

$I_{k}$ - moment bezwładności koła zamachowego,

$I_{r}$ - moment bezwładności całkowity wahadła,

$\phi$ - prędkość kątowa koła zamachowego,

$m_{c}$ - masa całkowita wahadła,

$g$ - przyspieszenie grawitacyjne,

$l_{p}$ - wysokość na której zawieszony jest środek masy wahadła,

$b_{\alpha}-$ współczynnik tarcia w osi wahadła,

$k$-wzmocnieni prądowe silnika,

$i$ - prąd twornika silnika,

$b_{\phi}-$ współczynnik tarcia w silniku.
Model (1), (2) nie może bezpośrednio posłużyć do kolejnych rozważań. Podczas dalszych prac posługiwać będziemy się dyskretnym filtrem oraz estymatorem, tym samym model (1), (2) (nieliniowy oraz ciągły) musi zostać poddany dyskretyzacji. $\mathrm{Na}$ tym etapie linearyzacja zostanie pominięta, natomiast kolejnym krokiem jest przeprowadzenie dyskretyzacji powyższego modelu. Zakładając zastosowanie uproszczonej metody dyskretyzacji można uzyskać dyskretne macierze równań stanu modelu (1), (2):

$$
\begin{aligned}
& A_{k}=\left[\begin{array}{ccc}
1 & T_{p} & 0 \\
\frac{m_{c} g l_{p} \sin (\alpha)}{I_{r}+I_{k}} T_{p} & 1-\frac{b_{\alpha}}{I_{r}+I_{k}} T_{p} & \frac{-b_{\phi}}{I_{r}+I_{k}} T_{p} \\
0 & 0 & 1-\frac{b_{\phi}}{I_{k}} T_{p}
\end{array}\right], \\
& B_{k}=\left[\begin{array}{c}
0 \\
\frac{k}{I_{r}+I_{k}} T_{p} \\
\frac{k}{I_{k}} T_{p}
\end{array}\right], \\
& C_{k}=\left[\begin{array}{lll}
1 & 0 & 0 \\
0 & 1 & 0 \\
0 & 0 & 1
\end{array}\right] \text {, } \\
& D_{k}=\left[\begin{array}{l}
0 \\
0 \\
0
\end{array}\right] \text {, }
\end{aligned}
$$

gdzie: $T_{p}$ - to okres próbkowania.

Model oparty o tak zdefiniowane macierze jest słuszny przy założeniu, że równania stanu posiadają następującą konstrukcję:

$$
\begin{gathered}
\underline{x}_{k+1}=A_{k} \underline{x}_{k}+B_{k} u_{k}, \\
\underline{y}_{k}=C_{k} \underline{x}_{k}+D_{k} u_{k},
\end{gathered}
$$

(gdzie: $u_{k}$ - to sygnał wejściowy modelu tj. prąd silnika, a $\underline{y}_{k}$ to wektor wyjścia, którego skład jest tożsamy z wektorem stanu) oraz, że wektor stanu składa się z następujących zmiennych:

$$
\underline{x}_{k}=\left[\begin{array}{c}
\alpha \\
\dot{\alpha} \\
\dot{\phi}
\end{array}\right],
$$

gdzie: kąt $\alpha$ odnosi się do odchylenia wahadła od pionu, prędkość kątowa $\dot{\alpha}$ określa częstość zmian kąta $\alpha$, natomiast $\dot{\phi}$ określa prędkość kątową koła zamachowego.

Pierwsze dwie wielkości wektora stanu mierzone są za pomocą akcelerometru i żyroskopu, a następnie estymowane przy użyciu filtru Kalmana użytego w formie fuzji sensorowej. Trzecia wielkość wektora stanu mierzona jest bezpośrednio przy użyciu enkodera inkrementalnego.

\section{Obserwator stanu}

Pomimo faktu posiadania dostępu do całkowitego wektora stanu (jego wszystkich składowych), autorzy zdecydowali się zastosować pełny obserwator stanu, bazujący na modelu matematycznym wahadła. Obserwator ten został zastosowany zgodnie z rysunkiem 5, opisującym całkowity schemat sterowania wahadła.

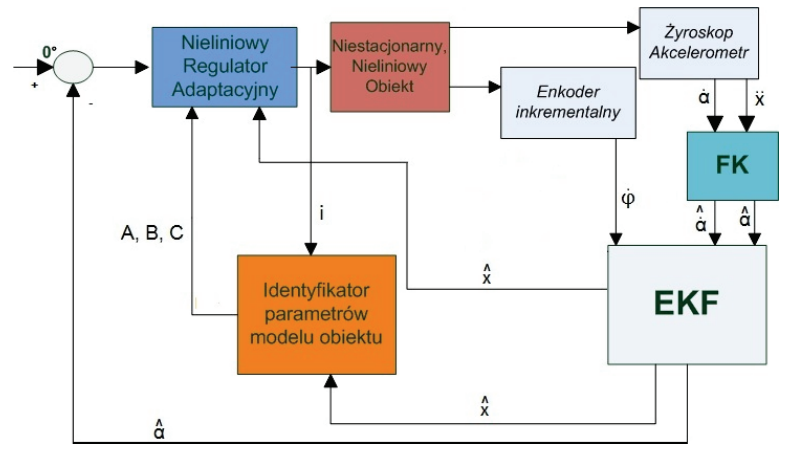

Rys. 5. Schemat sterowania wahadła, oznaczenia: FK - fuzja sensorów, EFK - rozszerzony filtr Kalmana 
Potrzeba zastosowania tego typu rozwiązania jest argumentowana silnie zaszumionymi sygnałami zarówno $\mathrm{z}$ fuzji sensorowej jak i z enkodera. Model matematyczny pobudzony jednakowym sygnałem jakim pobudzany jest obiekt sterowania, będzie symulować trajektorię generowaną poprzez wahadło. Trajektorie: symulowana jak i rzeczywista będą tożsame tylko w przypadku, gdy model matematyczny będzie wiernie odzwierciedlał dynamikę obiektu sterowania. Wprowadzenie zatem pełnego obserwatora stanu umożliwia dokonanie weryfikacji modelu jak i (w przypadku poprawności modelu) dokonanie lepszej estymacji wektora stanu.

$\mathrm{Na}$ mocy posiadanego modelu dyskretnego w ujęciu macierzowym (3), (4), (5), (6), można wprowadzić ogólną postać obserwatora stanu opartego o dwufazowy, rozszerzony filtr Kalmana (opisany w [2]):

a) faza predykcji:

$$
\begin{gathered}
\underline{\hat{x}}_{k}^{-}=f_{k}\left(\underline{\hat{x}}_{k-1}^{-}, u_{k-1}\right) \\
F_{k}=\frac{\partial f_{k}\left(\underline{\hat{x}}_{k-1}^{-}, u_{k-1}\right)}{\partial \underline{\hat{x}}_{\underline{x}_{\hat{x}}=\underline{x}_{k-1}}}=\frac{\partial\left[A_{k} \underline{\hat{x}}_{k-1}^{-}+B_{k} u_{k-1}\right]}{\left.\partial \underline{\hat{x}}\right|_{\hat{\underline{x}}=\underline{\hat{x}}_{k-1}}} \\
P_{k}^{-}=F_{k} P_{k-1} F_{k}^{T}+Q_{k}
\end{gathered}
$$

b) faza korekcji

$$
\begin{gathered}
H_{k}=\frac{\partial h\left(\hat{\hat{x}}_{k-1}^{-}\right)}{\partial \underline{\hat{x}}_{\underline{\hat{x}}=\underline{\hat{x}}_{k-1}}}=\frac{\partial\left[C_{k} \underline{\underline{x}}_{k-1}\right]}{\partial \underline{\hat{x}}_{\hat{\hat{x}}=\hat{x}_{k-1}}} \\
K_{k}=P_{k}^{-} H_{k}^{T}\left(H_{k} P_{k}^{-} H_{k}^{T}+R_{k}\right)^{-1} \\
\underline{\hat{x}}_{k}=\hat{\underline{x}}_{k}^{-}+K_{k}\left(\underline{z}_{k}-C_{k} \hat{\underline{x}}_{k}^{-}\right) \\
P_{k}=\left(I-K_{k} H_{k}\right) P_{k}^{-}
\end{gathered}
$$

W pierwszej fazie predykowany jest wektor stanu a priori $\hat{x}_{k}^{-}$. Jest to możliwe dzięki wyliczeniu wektora stanu $\mathrm{z}$ modelu o postaci nieliniowej oznaczonego jako $f_{k}$. Następnie dokonywana jest linearyzacja modelu w punkcie trajektorii, na której znajduje się obiekt sterowania, uzyskując tym samym macierz $F_{k}$. Ostatecznie, na koniec fazy predykcji obliczana jest macierz kowariancji $P_{k}^{-}$(również a priori).

W drugiej fazie, wektor stanu jest poddawany korekcie. Korekta ta bazuje na wektorze pomiarowym $\underline{Z}_{k}$ (złożonym ze składników wektora (9)), który koresponduje z wektorem stanu. Jako pierwsza, wyliczana jest macierz wyjścia $H_{k}$. Następnie, na podstawie tej macierzy jak i macierzy kowariancji $P_{k}^{-}$, obliczane jest wzmocnienie Kalmana $K_{k}$. W przedostatnim punkcie aktualizowany jest wektor stanu, a ostatecznie obliczona zostaje nowa macierz kowariancji.

Po całym cyklu działania obserwatora stanu, wynik zapisywany jest do wektora $\hat{x}_{k}$, dodatkowo zwiększony zostaje licznik iteracji - dokładnie tak jak pokazano to na rysunku 6 .

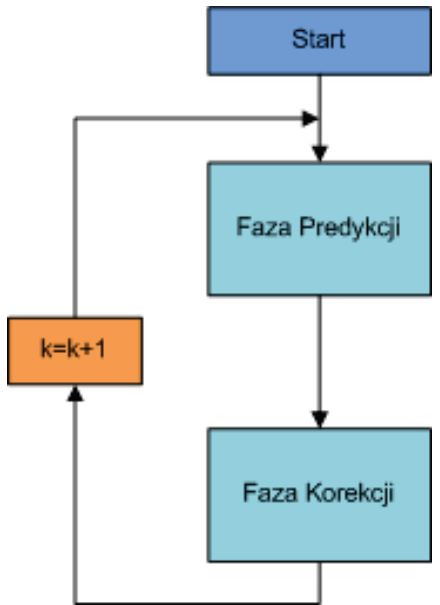

Rys. 6. Algorytm dziatania obserwatora stanu opartego o rozszerzony filtr Kalmana
Warto podkreślić, że rozszerzony Filtr Kalmana, działa $\mathrm{w}$ oparciu o dane zarówno $\mathrm{z}$ modelu matematycznego ( $\mathrm{w}$ fazie predykcji) jak i z czujników pomiarowych i fuzji sensorowej w fazie korekcji. Jest on zatem odporny na błędy modelowania, a tym samym estymata jest w każdym punkcie optymalna dla zdefiniowanych nastaw filtru. Estymator posiada dwa parametry, które można modyfikować, pierwszy to macierz wariancji procesu $Q_{k}$, a drugi to macierz wariancji pomiarów $R_{k}$. W przypadku zwiększenia pierwszego z dwóch wyżej wymienionych parametrów, zmniejszone zostanie „zaufanie" na dane generowane $\mathrm{w}$ fazie predykcji (oparte o model). Jeśli natomiast zwiększona zostanie wariancja $R_{k}$ wówczas spadnie „zaufanie" na wyniki pomiarów.

\section{Wyniki działania estymatora stanu}

Estymator zdefiniowany $\mathrm{w}$ poprzednim rozdziale został zaimplementowany $w$ jednostce sterującej wahadła. Kolejnym krokiem było wykonanie testów. Układ pomiarowy i jednostka sterująca zamknięte $\mathrm{w}$ jednej obudowie mikroprocesora zostały połączone z komputerem PC, na którym dokonano akwizycji wszystkich danych, zarówno wymuszeń jak i wyników z estymatora. Algorytmy fuzji sensorów, rozszerzonego filtru Kalmana oraz identyfikator parametrów modelu zostały zaimplementowane $\mathrm{w}$ aplikacji PC, tym samym do minimum ograniczono liczbę danych przesyłanych pomiędzy komputerem a układem sterującym. Podczas testów skupiono się głównie na porównaniu wyników działania estymatora przy różnych wartościach macierzy wariancji szumu procesu (macierz $Q_{k}$ ) oraz macierzy wariancji szumu pomiarowego (macierz $R_{k}$ ). Jako referencję przyjęto sygnał pomiarowy pochodzący $\mathrm{Z}$ fuzji sensorowej jak i $z$ enkodera. Dla równych nastaw tj. $Q_{k}=R_{k}=0,01$ wynik przedstawiono na rysunku 7 .

Jak widać, estymata nie zawiera szumu, który jest stowarzyszony z pomiarami z enkodera. Ciekawym aspektem jest też offset, który pojawia się $\mathrm{w}$ danych $\mathrm{z}$ enkodera (po zliczeniu impulsów), a który został skutecznie wyeliminowany przy wykorzystaniu estymatora.

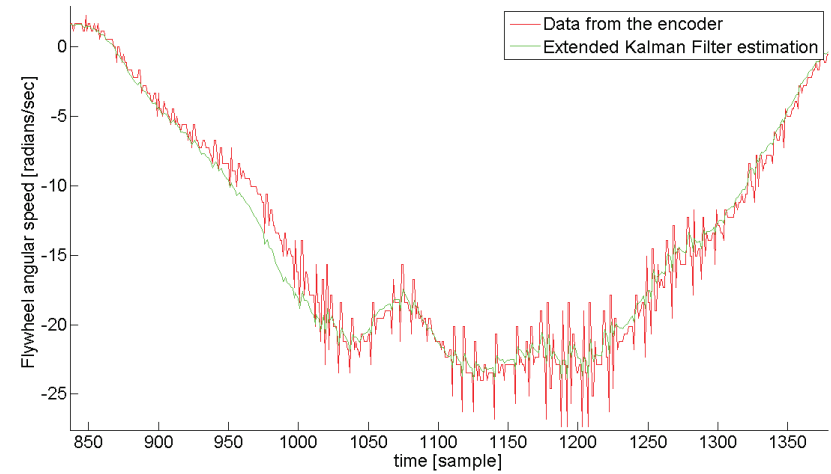

Rys. 7. Porównanie wyników estymaty obserwatora (kolor zielony) oraz pomiarów z enkodera (kolor czerwony)

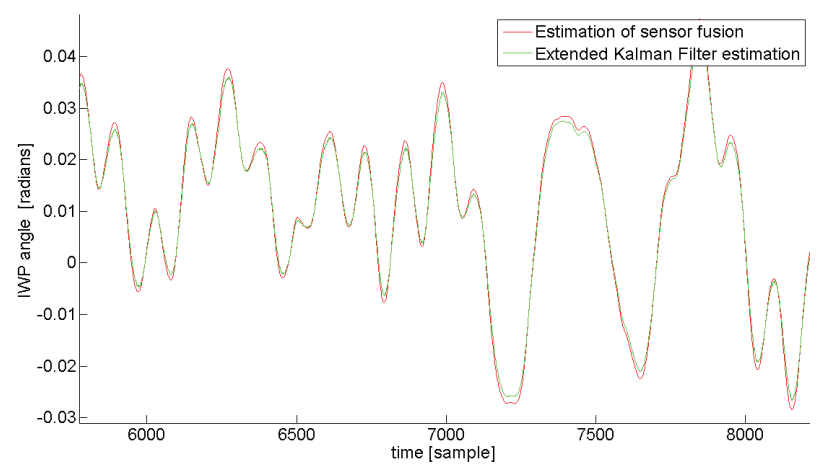

Rys. 8. Porównanie wyników estymaty obserwatora (kolor zielony) oraz estymaty z fuzji sensorów (kolor czerwony) 
W kolejnym kroku sprawdzono działanie estymtora dla kąta $\alpha$ oraz prędkości kątowej $\dot{\alpha}$. Był to kluczowy test, za pomocą którego można było sprawdzić, czy estymata uzyskana $\mathrm{z}$ filtru Kalmana działającego w konfiguracji fuzji sensorowej może być poprawiona poprzez rozszerzony Filtr Kalmana. Dla równych nastaw tj. $Q_{k}=R_{k}=0,01$ uzyskano wyniki przedstawione na rysunku 8 .

Jak widać estymaty nie różnią się od siebie, tym samym nie można wnioskować o poprawie wyniku podczas stosowania rozszerzonego estymatora. Na rysunku 9 pokazano wyniki eksperymentu dla innych nastaw tj. $R_{k}=0,1, Q_{k}=0,01$.

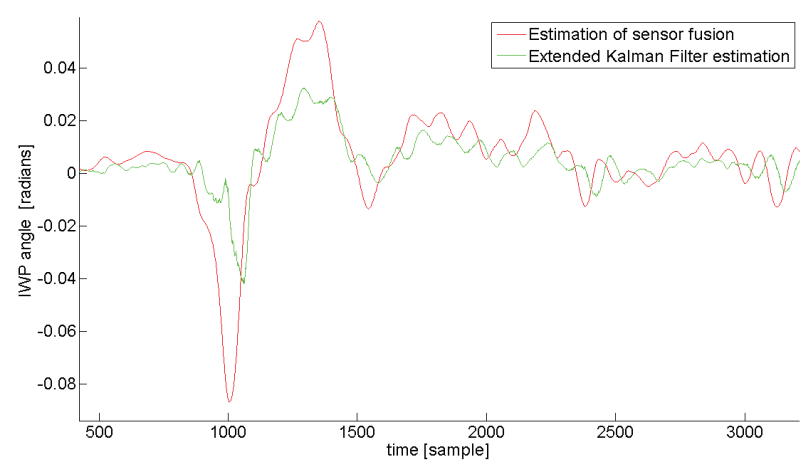

Rys. 9. Porównanie wyników estymaty obserwatora (kolor zielony) oraz estymaty z fuzji sensorów (kolor czerwony)

Dla takich nastaw, gdzie faza korekcji jest obarczona większym błędem (poprzez jawne zdefiniowanie wariancji szumu procesu), wynik rozszerzonego estymatora posiada ograniczoną amplitudę (sygnał jest osłabiony) oraz jest opóźniony. Dla tych nastaw rozszerzony estymator nie działa poprawnie oraz nie można mówić o poprawie wyniku fuzji sensorowej.

Zdecydowanie lepsze wyniki uzyskano dla prędkości kątowych wahadła. $\mathrm{Na}$ rysunku 10 przedstawiono wyniki działania estymatora dla prędkości kątowej wahadła. Można stwierdzić, że dzięki wykorzystaniu estymatora, możliwym stało się usunięcie offsetu prędkości kątowej, który nie został wyrugowany na etapie fuzji sensorów.

Po dokonaniu wnikliwej analizy, stwierdzono, że wynik fuzji sensorowej może być poprawiony tylko pod warunkiem pojawienia się skokowych zakłóceń na wejściu rozszerzonego filtru Kalmana lub w momencie pojawienia się offsetu w danych z żyroskopu. Offset ten nie może być wyeliminowany w przypadku stosowanie samej fuzji sensorów, co zostało potwierdzone po zastosowaniu rozszerzonego estymatora.

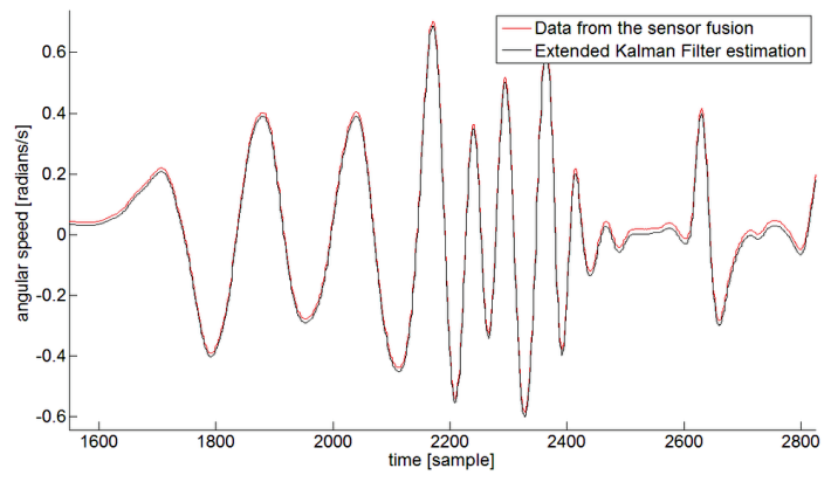

Rys. 10. Porównanie wyników estymaty obserwatora (kolor czarny) oraz estymaty z fuzji sensorów (kolor czerwony)

\section{Podsumowanie}

W pracy wprowadzono opis modelu matematycznego wahadła odwróconego, dla którego następnie stworzono obserwator wektora stanu. Obserwator pozwolił na estymację wszystkich zmiennych stanu, tym samym możliwym stało się zaimplementowanie sterowania uzależnionego bezpośrednio od wektora stanu (regulator $L Q$ ). Wyniki działania rozszerzonego estymatora wektora stanu można podzielić na trzy części. Pierwsza to wyniki dotyczące bezpośrednio kąta odchylenia wahadła od pionu. W tej części nie można mówić o zdecydowanej poprawie estymaty. Druga część dotyczy estymacji prędkości kątowej. Jak się okazało, estymator umożliwił pozbycie się offsetu prędkości, która nie została usunięta na poziomie fuzji sensorowej.

Trzecia część dotyczy prędkości kątowej koła zamachowego. W przypadku tej wielkości wyniki estymatora były zadawalające, natomiast jego zastosowanie pomogło usunąć zakłócenia stowarzyszone $\mathrm{z}$ sygnałem $\mathrm{z}$ enkodera.

Reasumując stwierdza się poprawę estymacji w stosunku do fuzji sensorów oraz pomiarów $\mathrm{z}$ enkodera. Użycie rozszerzonego filtru Kalmana pozwoliło na zastosowanie docelowego sterowania oraz na ustabilizowanie wahadła.

\section{Literatura}

[1] Gośliński J., Owczarkowski A.: Control and model parameters identification of inertia wheel pendulum. Proceedings of 9th International Conference on Informatics in Control, Automation and Robotics, Rzym, 2012.

[2] Królikowski A., Horla D.: Identyfikacja Obiektów Sterowania, Wyd. 2, Wydawnictwo Politechniki Poznanskiej, Poznań 2005.

[3] Spong, M. W., P. Corke, R. L.: Nonlinear control of the inertia wheel pendulum. In research under grants CMS-9712170 and ECS-9812591, Urbana, Kenmore, France 1999.

\section{Mgr inż. Adam Owczarkowski \\ e-mail: \\ adam.j.owczarkowski@doctorate.put.poznan.pl \\ W 2011 roku ukończył studia o kierunku Automatyka i Robotyka na Wydziale Elektrycznym Politechniki Poznańskiej. Od tego czasu, jest studentem studiów doktoranckich na tej samej uczelni. Jego praca głównie skupia się na sensoryce opartej o technologię MEMS, algorytmach sterowania robotów i implementacji ich w systemach} wbudowanych z układami FPGA.
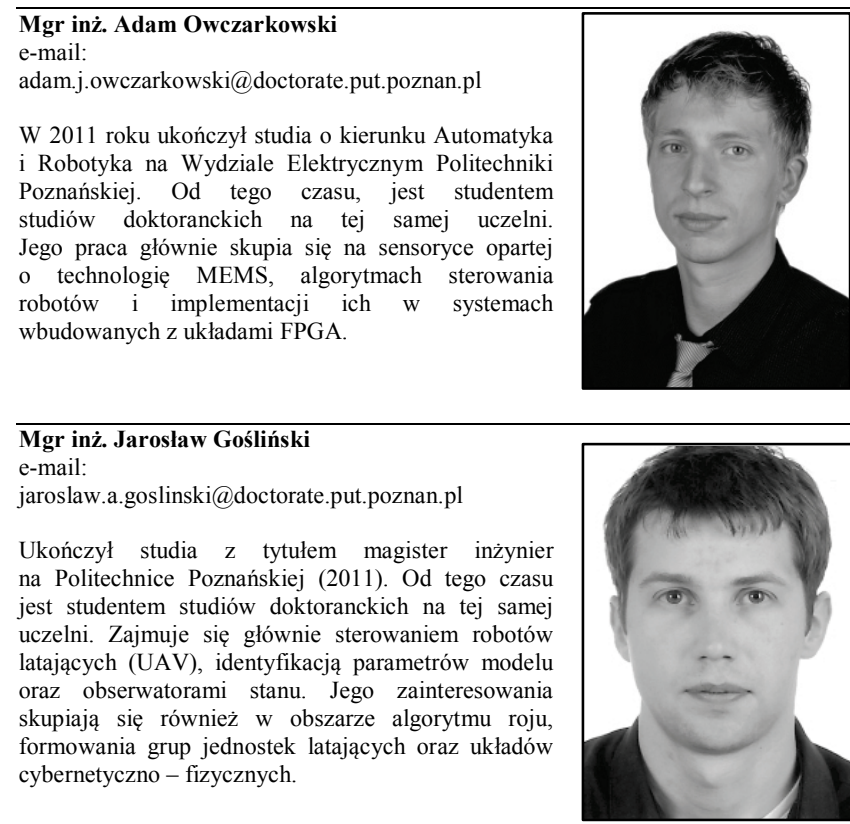

Artykuł recenzowany 